\title{
Fatigue damage modelling of adhesively bonded joints under variable amplitude loading using a cohesive zone model
}

\author{
H. Khoramishad ${ }^{\mathrm{a}}$, A.D. Crocombe $\mathrm{K}^{\mathrm{b}, 1}$, K.B. Katnam ${ }^{\mathrm{b}}$ and I.A. Ashcroft ${ }^{\mathrm{c}}$ \\ ${ }^{a}$ Department of Mechanical Engineering, Iran University of Science and Technology, \\ Narmak, Tehran, 16846, Iran \\ ${ }^{\mathrm{b}}$ Mechanical, Medical and Aerospace Engineering, Faculty of Engineering and Physical Sciences \\ (J5), University of Surrey, Guildford, Surrey GU2 7XH, UK \\ ${ }^{c}$ Wolfson School of Mechanical and Manufacturing Engineering, Loughborough University, \\ Leicestershire LE11 3TU, UK
}

\begin{abstract}
In this paper, the fatigue response of adhesively bonded joints under variable amplitude (VA) cyclic loading was predicted using a numerical model. The adhesive layer was modelled using the cohesive zone model with a bi-linear traction-separation response. A damage model, incorporating fatigue load ratio effects, was utilised in conjunction with the cohesive zone model to simulate the detrimental influence of VA fatigue loading. This model was validated against published experimental results obtained from fatigue tests of adhesively bonded single lap joints subjected to various types of VA fatigue loading spectra. This model successfully predicted the damaging effect of VA fatigue loading on the adhesively bonded joints and was generally found to be a significant improvement on the other damage models considered.
\end{abstract}

Key words: Variable amplitude fatigue, Adhesively bonded joints, Cohesive zone model, Fatigue damage modelling, Process zone

\section{Introduction}

Adhesively bonded joints are increasingly being utilised in various industries because of their well recognised advantages over the classical mechanical fastening methods. Nevertheless, there are a few aspects that prevent a more widespread use of adhesive bonding over the traditional joining techniques such as riveting and bolting. The major concerns include the

\footnotetext{
${ }^{1}$ Corresponding author. Tel.: +44 (0)1483 689194;

E-mail address: a.crocombe@surrey.ac.uk
} 
necessity for good surface preparation and the vulnerability to hostile environments and fatigue loading. It is worth noting that the susceptibility to fatigue damage has been recognised as an important concern in bonded joints, even though adhesively bonded joints exhibit a better fatigue performance than equivalent conventional fasteners [1]. This is because fatigue is still one of the most common causes of failure in structures in general. This has resulted in engineers considering fatigue damage tolerance as one of the key parameters in designing adhesively bonded joints.

The mechanical behaviour of structures under fatigue loading can be studied purely experimentally or through a combined numerical experimental study. However, fatigue testing is often costly and time consuming and predictive numerical models can help in reducing time and cost. The predictive models can effectively enable engineers to minimise the experimental effort required to attain a reliable and efficient structural design. Nevertheless, less research has been undertaken in developing fatigue lifetime prediction techniques for adhesively bonded joints than in undertaking fatigue testing.

Fatigue damage in adhesively bonded joints has been studied with constant and variable amplitude loading. Due to the complexity of VA loading, less experimental and predictive studies have been undertaken in this area. However, actual structures such as aircraft and automobile components generally experience irregular fatigue loading spectra and simplifying these to constant amplitude (CA) loading is not representative of the actual loading experienced by the structure. This is because of the significant differences between the responses of structures under constant and variable amplitude loading. One of the major differences is the load interaction that occurs due to the load shifts in a VA loading spectrum. This load interaction can considerably affect the fatigue behaviour of the structure. This effect can be different depending on the type of material. For instance, in ductile materials such as aluminium, the presence of the overloads in loading spectra can lead to crack retardation [2] whereas in relatively more brittle materials such as adhesives [3] and composite materials [4] overloads can give rise to crack growth acceleration. Researchers have explained these different effects by studying the influence of the load shifts on the region ahead of the crack (damage) front. They observed that for ductile materials the presence of the overloads in the loading spectra induce compressive residual stresses in the plastic zone ahead of the crack front or cause crack tip closure or blunting and decrease the crack growth rate [5]. Whilst in 
the case of relatively brittle materials such as adhesives, researchers reported an increase in the process (damage) zone ahead of the crack front causing the crack growth acceleration [3].

Some methods have been developed to predict the fatigue life of bonded joints under VA fatigue loading [6-9]. However, they are either empirical (providing limited understanding of the underlying mechanisms) or are unable to take important VA fatigue characteristics (such as load shifts) into account. Therefore, they were not able to provide reasonable predictions resulting in highly conservative or highly unconservative fatigue life predictions.

The fatigue response of the adhesively bonded joints under VA cyclic loading has been studied and reported in this paper. A fatigue damage model developed by the authors [10] for CA fatigue loading was adapted to predict the experimental results reported by Shenoy et al. [9] for single lap joints (SLJs) subjected to VA loading. This paper is organised into three main sections: first, the main predictive models that have been used by others to predict the VA fatigue life of adhesively bonded joints are outlined. Then, the experimental results used for the model validation are summarised. Finally, the proposed numerical model was described and the predicted results were compared with the experimental data and with the predictions obtained using other approaches.

\section{Predictive models for VA fatigue}

Some of the methods employed for fatigue prediction of bonded joints under VA loading include total life, strength wearout, fracture mechanics based and damage mechanics based methods [6-9]. The total life method expresses the fatigue life as a function of a loading variable such as the maximum or the amplitude of the stress, strain or load cycle. This method was extended by Palmgren [11] and Miner [6] to predict the VA fatigue life. They assumed linear accumulation of fatigue damage throughout the VA fatigue spectrum. The VA fatigue life can be predicted based on this method using the Palmgren-Miner rule (Eq. 1).

$$
N_{B} \sum_{i=1}^{n_{S}} \frac{n_{i}}{N_{i}}=1
$$


in Eq. $1, N_{\mathrm{B}}$ is the number of repeated VA loading blocks to failure, $n_{\mathrm{S}}$ is the number of CA stages in the VA loading block, $n_{\mathrm{i}}$ is the number of cycles in the CA stage which has a total fatigue life of $N_{\mathrm{i}}$. The parameter $N_{\mathrm{i}}$ can be obtained from the load-life curves of CA fatigue tests. However, this simple method is not able to indicate the damage or the evolution of the damage during the fatigue loading and cannot differentiate between the damage initiation and propagation phases of fatigue lifetime. More importantly, this method does not take the load interaction into account and therefore, depending on the type of material, it tends to overestimate or underestimate the fatigue life.

The strength wearout approach [7] has been used to predict the VA fatigue life. In this approach, the reduction in initial strength is measured by conducting partial fatigue tests on the adhesively bonded joints to induce partial failure followed by a quasi-static test up to complete failure. The strength decreases with increasing cycles from the initial static strength to the maximum fatigue load level. In this approach an empirical equation (linear [3] or nonlinear [12]) is fitted to the experimental results to relate the strength reduction to the number of fatigue cycles. This approach was extended to predict the fatigue life of the bonded joints subjected to the VA fatigue loading by Schaff and Davidson [4,13]. They predicted the VA fatigue life based on the strength wearout curves obtained from CA fatigue testing. They further improved this method by incorporating a correction factor termed as cycle mix factor to account for the loading interaction causing the damage acceleration due to the shift from one CA stage to another in the VA fatigue spectrum. The strength wearout approach can predict the fatigue life of the bonded joints under the VA fatigue loading more accurately than the Palmgren-Miner's law [3]. However, this destructive approach requires a strength wearout curve for each of the CA stages of the VA loading block and consequently needs a series of experimental testing for each of the CA stages. Moreover, this method does not take into account the load history and is not able to differentiate between the damage initiation and propagation phases of fatigue lifetime.

The two approaches outlined above require tests to be carried out for the specific joints under consideration. The approaches that follow are more generic, seeking to determine the joint response from the underlying material behaviour. A fracture mechanics based method (fatigue crack growth approach) that has been used widely for CA fatigue prediction of bonded joints has been utilised to predict VA fatigue response $[8,9,14]$. This method relates the fatigue crack growth rate to an appropriate facture mechanics parameter through an empirical 
equation. The strain energy release rate was found to be the appropriate facture mechanics parameter for cracks along the interface in bi-material samples like an adhesive-substrate interface [15]. Erpolat et al. [14] performed a simple crack growth integration to predict the VA fatigue life of composite double cantilever beam joints using the CA fatigue crack growth curves. Their predicted crack size increased throughout a CA stage at a fixed crack growth rate, obtained from the corresponding CA fatigue crack growth data. This procedure was repeated until the strain energy release rate exceeded the critical fracture energy. However, they significantly underestimated the fatigue crack growth rate because of the crack growth acceleration due to load interaction. Ashcroft [8] improved the method by introducing a parameter to shift the CA fatigue crack growth curve to the left to account for the crack growth acceleration observed. He employed this model for a composite strap lap joint under a CA loading spectrum having periodic overloads. However this parameter is dependent on the number and magnitude of the overloads and consequently needs to be determined for every loading spectrum. The fracture mechanics based approach does not take the initiation phase of fatigue life into account therefore it tends to under-predict the fatigue life which may not be negligible.

Continuum damage mechanics has been employed to predict the fatigue response of adhesively bonded joints [e.g. 16,17]. In this method, a damage variable is defined which modifies the constitutive response of the adhesive. Shenoy et al. [9] utilised this method for the fatigue prediction of the SLJ under VA loading. They assumed the damage rate to be a power law function of the plastic strain range and degraded the plastic behaviour of the adhesive based on this damage variable. However, they significantly over-predicted the fatigue life of the adhesively bonded joints under VA loading using this continuum damage mechanics based approach. Moreover, as the damage rate was a function of plastic strain, the model may not be appropriate for predicting fatigue response under high cycle fatigue loading. Furthermore, the authors stated that the model parameters were mesh size dependant.

Extensive work has been conducted in the application of CZM in predicting fatigue response under CA fatigue loading [e.g. 18-21]. However, less work has been carried out using the CZM based fatigue model for variable amplitude loading [22,23]. In that work, fatigue loading was modelled cycle by cycle which was computationally expensive and practically impossible in case of high cycle fatigue. Siegmund [22] used the CZM model developed by Roe and Siegmund [18] to simulate the fatigue damage in double cantilever beam specimens 
having aluminium substrates bonded with a modified high-density polyethylene based adhesive under variable amplitude loading. He modelled the effect of overload and two-phase loading spectra with fixed load ratio and load range, respectively, using a cycle-by-cycle based fatigue model.

Jiang et al. [23] modelled the influence of a single overload interspersed in a CA cyclic loading on aluminium compact-tension-shear specimens for different load ratios. They used a cycle-by-cycle fatigue model based on the CZM. They observed compressive residual stress due to the overloads giving rise to crack retardation. This crack retardation tended to be dependent on the mode ratio, as it was found to be greater for mode I than for mode II.

\section{Experimental work}

The experimental results of the tests performed by Shenoy et al. [9] on the SLJs shown in Fig. 1 , were used to validate the model methodology. The substrates, cut from $2.5 \mathrm{~mm}$ thick sheets of 7075-T6 aluminium alloy, were bonded using the toughened epoxy film adhesive FM 73M.

\section{Fig. 1. Single lap joint}

The substrates were pre-treated using a patented alternating current, direct current (ACDC) anodisation process [24] followed by the application of the BRß 127 corrosion inhibiting primer. They studied the structural response of the SLJ under quasi-static, CA fatigue and VA fatigue loading. A static strength of $11.95 \pm 0.31 \mathrm{kN}$ was obtained by applying the quasi-static loading with a constant displacement rate of $0.1 \mathrm{~mm} / \mathrm{min}$. Moreover, the SLJs were tested under load-controlled fatigue loading. The CA fatigue tests were conducted at various load levels with a load ratio of 0.1 and frequency of $5 \mathrm{~Hz}$. Various types of two-stage VA fatigue loading spectra were also applied to the SLJs. These VA fatigue loading spectra are illustrated schematically in Fig. 2.

\section{Fig. 2. Various VA fatigue loading spectra}

As shown in Fig. 2, four different types of VA fatigue loading were applied to the SLJs. In type $\mathrm{A}$, the load ratios of the two stages were kept constant and the load amplitude $\left(\mathrm{P}_{\mathrm{a}}\right)$ and 
mean load $\left(\mathrm{P}_{\mathrm{m}}\right)$ were varied. In type $\mathrm{B}$, the load amplitude was kept constant and the other two parameters were changed. In type $\mathrm{C}$, the mean load was kept constant and the other two parameters were varied. Finally, in type D, overloads were introduced while the minimum load level was kept constant. The fatigue responses of the SLJs under these four types of VA fatigue loading with the parameters summarised in Table 1 were predicted using the numerical model proposed in this paper.

Table 1. VA fatigue loading spectra descriptions

\begin{tabular}{|c|c|c|c|c|c|c|c|c|c|}
\hline \multirow{2}{*}{$\begin{array}{c}\text { VA fatigue } \\
\text { loading } \\
\text { spectra }\end{array}$} & \multicolumn{4}{|c|}{ Loading conditions } & \multicolumn{2}{|c|}{ Cycles } & \multicolumn{3}{|c|}{$\%$ changes in } \\
\hline & $\begin{array}{l}\mathbf{P}_{\max 1} \\
(\mathbf{k N})\end{array}$ & $\begin{array}{l}\mathbf{P}_{\max 2} \\
(\mathrm{kN})\end{array}$ & $\mathbf{R}_{1}$ & $\mathbf{R}_{2}$ & $\mathbf{n}_{1}$ & $\mathbf{n}_{2}$ & $\mathbf{R}$ & $\mathbf{P}_{\mathrm{a}}$ & $\mathbf{P}_{\mathbf{m}}$ \\
\hline $\mathbf{A}$ & 6.5 & 8 & 0.1 & 0.1 & 10 & 5 & 0 & 23 & 23 \\
\hline B & 6.5 & 8 & 0.1 & 0.27 & 10 & 5 & 169 & 0 & 42 \\
\hline $\mathbf{C}$ & 6.5 & 7 & 0.1 & 0.02 & 10 & 5 & -80 & 17 & 0 \\
\hline D & 6.5 & 8 & 0.1 & 0.08 & 10 & 1 & -19 & 26 & 21 \\
\hline
\end{tabular}

Three tests were conducted by Shenoy et al. [9] for every type of the VA spectrum and the mean fatigue lives of 6379, 8969, 16753 and 8987 cycles and percentage deviations of $84 \%$, $20 \%, 50 \%$ and $34 \%$ were obtained for the spectra A, B, C and D, respectively. Moreover, the fatigue lives obtained for the VA spectra A, B, C and D were 0.07, 0.1, 0.19 and 0.1 of the fatigue life obtained for the first $\mathrm{CA}$ stage of each spectrum, i.e. $\mathrm{P}_{\max }=6.5 \mathrm{kN}, \mathrm{R}=0.1$ [9].

A subsidiary set of fatigue experimental results were used for part of the calibration methodology in Sec. 4.2.1. This set of experimental tests was obtained by conducting CA fatigue tests at different load ratios and load levels on SLJs with 2024-T3 aluminium substrates bonded with FM 73M OST toughened epoxy film adhesive. In this SLJ the overlap length, the adhesive thickness, the substrate thickness and the substrate free length were 30 $\mathrm{mm}, 0.2 \mathrm{~mm}, 4.7 \mathrm{~mm}$ and $45 \mathrm{~mm}$, respectively.

In the subsidiary set of tests, the fatigue damage evolution was assessed using the backface strain technique. In the backface strain technique, strain gauges are bonded on the backface of the substrate, near a site of anticipated damage and, while the test is running, the strain variation is recorded. This variation of strain can be linked to the evolution of damage. This is because damage initiation and propagation directly influence the deformation of the substrates and consequently cause variations in the substrate strain. The backface strain technique was 
initially employed by Abe and Satoh [25] to study crack initiation and propagation in welded structures. Later, several authors [e.g 26-28] have applied this technique to adhesively bonded joints.

\section{Finite Element Modelling}

\subsection{Static modelling}

A finite element model, shown in Fig. 3, was developed in ABAQUS/Standard to predict the static response of the SLJ. Four-node plane stress elements (CPS4) were used for the substrates and four-node cohesive elements (COH2D4) with a bi-linear traction-separation response were utilised to study the progressive damage in the adhesive bond line. The boundary conditions used are shown in Fig. 3. The left boundary of the upper substrate was encastre. The transverse displacement and the rotation at the right boundary of the lower substrate were constrained. The size of the cohesive element was $0.1 \times 0.2 \mathrm{~mm}$ throughout the adhesive bond line. This element size was determined by undertaking a mesh convergence study. It's worth mentioning that the tabbed regions shown in Fig. 1 are fully held within the grips whilst the FE model (Fig. 3) only shows the regions between the grips. The zero slope mimics the rigid grips.

Fig. 3. Finite element mesh and boundary conditions

The stress-strain curve of 7075-T6 aluminium alloy [29] shown in Fig. 4 was used for the substrates.

Fig. 4. Stress-strain curve for 7075-T6 aluminium alloy [29]

The cohesive zone model (CZM) is currently considered as the most efficient method for simulating the progressive damage that occurs when loading adhesively bonded joints. This model was introduced by Barenblatt [30,31] and incorporated into a computational framework by Hillerborg et al. [32]. The CZM was developed in a continuum damage mechanics framework and utilised fracture mechanics concepts to improve its applicability. Fig. 5 shows a schematic representation of a mixed-mode cohesive zone model. The bi-linear tractionseparation responses under peel, shear and mixed-mode stress states are illustrated. Points A 
and $\mathrm{B}$, corresponding to the damage initiation and full failure conditions of mixed-mode response, are defined based on mixed-mode damage initiation and propagation criteria, respectively, details of which are given later.

\section{Fig. 5. Mixed-mode bi-linear traction-separation law}

The defining parameters of the mixed-mode traction-separation response include the fracture energies for mode I and mode II $\left(G_{\mathrm{IC}}\right.$ and $\left.G_{\mathrm{IIC}}\right)$, the tripping tractions for mode I and mode II ( $T_{\mathrm{I}}$ and $T_{\mathrm{II}}$ ), the initial stiffnesses for mode-I and mode-II $\left(E_{\mathrm{I}}\right.$ and $\left.E_{\mathrm{II}}\right)$ and the mixed-mode criteria for both damage initiation and propagation. These parameters are explained in more detail elsewhere [33].

To calibrate the CZM parameters, the critical strain energy release rate obtained by Shenoy et al. [9] by conducting standard fracture mechanics tests was considered as the fracture energy and the tripping traction was obtained by correlation between the simulated and the experimental failure load. The initial stiffness was actually taken as the adhesive Young's modulus. The calibrated cohesive zone model parameters are summarised in Table 2.

Table 2. Calibrated traction-separation response

\begin{tabular}{cccc}
\hline $\begin{array}{c}\text { Tripping traction } \\
\text { normal (shear) } \\
\mathbf{M P a}\end{array}$ & $\begin{array}{c}\text { Fracture energy } \\
\text { mode I (mode II) } \\
\mathbf{k J} / \mathbf{m}^{\mathbf{2}}\end{array}$ & Initiation criterion & Propagation criterion \\
\hline $72(42)$ & $2(4)$ & $\begin{array}{c}\text { Maximum nominal } \\
\text { stress criterion }\end{array}$ & $\begin{array}{c}\text { Benzeggagh-Kenane (BK) } \\
(\text { with } \eta=2)\end{array}$ \\
\hline
\end{tabular}

The Maximum nominal stress criterion (Eq. 2) signifies that damage is assumed to initiate when either the peel or shear component of traction $\left(t_{I}\right.$ or $\left.t_{I I}\right)$ exceeds the respective critical value $\left(T_{I}\right.$ or $\left.T_{I I}\right)$.

$$
\max \left\{\frac{\left\langle t_{I}\right\rangle}{T_{I}}, \frac{t_{I I}}{T_{I I}}\right\}=1
$$

in which \langle\rangle is the Macaulay bracket meaning that the compression stress state does not lead to the damage initiation. The Benzeggagh-Kenane (BK) [34] criterion is defined in Eq. 3. 


$$
G_{I C}+\left(G_{I I C}-G_{I C}\right)\left(\frac{G_{I I}}{G_{I}+G_{I I}}\right)^{\eta}=G_{I}+G_{I I}
$$

where $G_{I}$ and $G_{I I}$ are the energies released by the traction due to the respective separation in normal and shear directions, $G_{I C}$ and $G_{I I C}$ are the critical fracture energies required for failure in the normal and shear directions, respectively and $\eta$ is a material parameter.

A value of $11.94 \mathrm{kN}$ was predicted for the static strength using the calibrated CZM parameters (Table 2). This was in good correlation with the experimentally measured value of $11.95 \pm 0.31 \mathrm{kN}[9]$.

\subsection{Fatigue modelling}

\subsubsection{Constant amplitude loading}

A fatigue damage model was developed by the authors [33] in which fatigue loading was characterised by a constant load equal to the maximum fatigue load. This model was generalised [10] to accommodate the effect of load ratio. The generalised model was employed to predict fatigue response of adhesively bonded joints under CA cyclic loading of different load ratios using the same material damage parameters. In this current paper, this model has been adapted for VA fatigue loading.

In the proposed fatigue model, the fatigue loading is characterised by the maximum fatigue load and the fatigue damage was simulated by degrading the cohesive properties of the adhesive bond line using a fatigue damage evolution law. The basic fatigue damage evolution law reported in [33] is presented in Eq. 4.

$$
\begin{aligned}
& \frac{\Delta D}{\Delta N}= \begin{cases}\alpha\left(\bar{\varepsilon}_{\text {max }}-\bar{\varepsilon}_{t h}\right)^{\beta}, & \bar{\varepsilon}_{\text {max }}>\bar{\varepsilon}_{t h} \\
0, & \bar{\varepsilon}_{\text {max }} \leq \bar{\varepsilon}_{t h}\end{cases} \\
& \bar{\varepsilon}_{\text {max }}=\frac{\bar{\varepsilon}_{n}}{2}+\sqrt{\left(\frac{\bar{\varepsilon}_{n}}{2}\right)^{2}+\left(\frac{\bar{\varepsilon}_{s}}{2}\right)^{2}}
\end{aligned}
$$

where $\Delta D$ is the increment of damage and $\Delta N$ is the cycle increment. $\bar{\varepsilon}_{n}$ and $\bar{\varepsilon}_{t}$ refer to averaged bondline thickness normal and tangential strains which are the normal and tangential 
displacement components of the cohesive zone element divided by the adhesive thickness. $\bar{\varepsilon}_{\text {max }}$ is a combination of normal and shear components $\left(\bar{\varepsilon}_{n}\right.$ and $\left.\bar{\varepsilon}_{t}\right), \bar{\varepsilon}_{t h}$ is a threshold value (below which no fatigue damage occurs) and $\alpha, \beta$ and $\bar{\varepsilon}_{t h}$ are fatigue model parameters which need to be calibrated against the experimental tests. More detail of this model can be found in [33].

To model the actual fatigue loading, in addition to the maximum fatigue load, another characteristic of the fatigue loading needs to be incorporated into the model. In the proposed fatigue damage model, this was accommodated by using the load ratio $R$. To accommodate the load ratio effect, it was suggested that the fatigue loading be projected to the corresponding fully reversed $(R=-1)$ load point. To illustrate this, a schematic fatigue master diagram, representing all fatigue loading characteristics including maximum $\left(P_{\max }\right)$, minimum $\left(P_{\min }\right)$, amplitude $\left(P_{\mathrm{a}}\right)$, mean $\left(P_{\mathrm{m}}\right)$ loads and load ratio $(R)$, is illustrated in Fig. 6. In this figure, two points (A and B) with the same maximum fatigue load of $P_{\max , \mathrm{AB}}$ but different load ratios of $R_{\mathrm{A}}$ and $R_{\mathrm{B}}\left(R_{\mathrm{A}}<R_{\mathrm{B}}\right)$ are shown. Two curves $\left(\mathrm{P}_{\mathrm{S}} \mathrm{A}^{\prime}\right.$ and $\left.\mathrm{P}_{\mathrm{S}} \mathrm{B}^{\prime}\right)$ passing though the points $\mathrm{A}$ and $\mathrm{B}$ correspond to constant fatigue lives of $N_{\mathrm{A}}$ and $N_{\mathrm{B}}$, respectively. These empirical curves represent all possible combinations of fatigue loading that result in constant fatigue lives of $N_{\mathrm{A}}$ and $N_{\mathrm{B}}$, respectively. It is expected that when $P_{\mathrm{a}}$ is zero $P_{\mathrm{m}}$ must equal the static strength $\left(P_{\mathrm{S}}\right)$ for failure to occur.

Fig. 6. A schematic of fatigue master diagram

As shown in Fig. 6, the points A and B were projected to the points A' and B' respectively in the fully reversed load condition. For this, a correction factor was derived using empirical constant-life equations such as linear Goodman or parabolic Gerber equations (Eq. 5).

$\frac{P_{a}}{\overline{P_{a}}}+\left(\frac{P_{m}}{P_{s}}\right)^{m}=1, \quad \begin{aligned} & m=1, \text { for Goodman } \\ & m=2, \text { for Gerber }\end{aligned}$

In Eq. (5), $P_{a}$ and $P_{m}$ are the load amplitude and mean fatigue load, respectively, and $\overline{P_{a}}$ is the equivalent load amplitude at $R=-1$ (fully reversed), that has the same fatigue life as the arbitrary fatigue load with amplitude and mean loads of $P_{a}$ and $P_{m}$, respectively. $P_{s}$ is the 
ultimate static strength of the bonded joint. By solving Eq. (5) for $\overline{P_{a}}$ and substituting $P_{a}$ and $P_{m}$ with $P_{\max }(1-R) / 2$ and $P_{\max }(1+R) / 2$ respectively, Eq. (6) can be obtained.

$$
\begin{aligned}
& \overline{P_{a}}=P_{\max } \gamma \\
& \gamma=\frac{(1-R) / 2}{1-\left[\frac{P_{\max }}{2 P_{S}}(1+R)\right]^{m}}, \quad \begin{array}{l}
m=1, \text { for Goodman } \\
m=2, \text { for Gerber }
\end{array}
\end{aligned}
$$

Any combination of $P_{a}$ and $P_{m}$ on the constant-life diagrams (such as Goodman or Gerber) can be projected to the corresponding fully reversed $(R=-1)$ load point $\left(\overline{P_{a}}\right)$ by multiplying the maximum fatigue load by the corresponding correction factor $\gamma$. As the correction factor is a function of load ratio, by utilising $\overline{P_{a}}$ as the numerically applied maximum load, the load ratio can be incorporated into the model. Alternatively, the maximum load can be assumed as the actual maximum fatigue load and the fatigue damage evolution can be modified based on the correction factor obtained in Eq. (6). This fatigue damage evolution modification is shown in Eq. 7. More detail about this fatigue damage evolution modification can be found in [10].

$$
\begin{aligned}
& \frac{\Delta D}{\Delta N}= \begin{cases}\alpha\left[\left(\bar{\varepsilon}_{\text {max }}-\bar{\varepsilon}_{t h}\right) \gamma^{n}\right]^{\beta}, & \bar{\varepsilon}_{\text {max }}>\bar{\varepsilon}_{t h} \\
0, & \bar{\varepsilon}_{\text {max }} \leq \bar{\varepsilon}_{t h}\end{cases} \\
& \bar{\varepsilon}_{\text {max }}=\frac{\bar{\varepsilon}_{n}}{2}+\sqrt{\left(\frac{\bar{\varepsilon}_{n}}{2}\right)^{2}+\left(\frac{\bar{\varepsilon}_{s}}{2}\right)^{2}}
\end{aligned}
$$

It should be noted that because $\gamma$ was derived as a correction factor for the load, when applying it to the averaged bondline thickness strain in the damage evolution law, the ductility needs to be taken into account. This ductility comes from the adhesive which displays a nonlinear traction separation response. This is because, for a given stress change, a more ductile material exhibits larger averaged bondline thickness strain variation. This is considered by incorporating the power $n$ in the damage evolution law (Eq. 7). The two approaches based on the maximum load and fatigue damage evolution modifications are illustrated in Fig. 7.

Fig. 7. Fatigue model modifications 
It was found that the fatigue life can be successfully predicted using both of the modifications but the predicted damage evolutions were significantly different. Fig. 8 compares the predicted fatigue lives and damage evolution obtained using the models based on both the $P_{\max }$ modification and the fatigue damage evolution modification with the subsidiary set of fatigue experimental results. As shown in Fig. 8a, the load-life curves predicted by both of the approaches were in good correlation with the experimental results. Conversely, the predicted damage evolutions were considerably different (see Fig. 8b).

Fig. 8. Comparison between the $P_{\max }$ and fatigue damage evolution law modifications, a) load-life data, b) backface strain data for $R=0.1$ and $P_{\max } / P_{S}=0.5$

As is evident from Fig. 8b, the approach based on the damage evolution law modification could successfully predict the backface strain data whereas the approach based on the $\mathrm{P}_{\max }$ modification was not able to do so. The data shown is for $R=0.1$ but a similar difference was also found for the $R=0.5$ data with the damage evolution modification producing backface strains much closer to the measured values than the $\mathrm{P}_{\max }$ modification. Therefore the damage evolution modification approach (rather than the $\mathrm{P}_{\max }$ modification approach) was employed for the VA fatigue prediction.

\subsubsection{Variable amplitude loading}

The fatigue model based on the damage evolution modification was used to predict the fatigue response of adhesively bonded joints under VA cyclic loading. The numerically applied load was considered in blocks equal to the maximum fatigue load levels of the separate CA loading stages. This is shown in Fig. 9. In step one, the maximum fatigue load of the first CA stage in the VA spectrum was applied and the intact joint was analysed under static, undamaged conditions providing the state at the beginning of the fatigue loading. At this point, a fatigue damage variable was introduced into the model at all adhesive element integration points. This fatigue damage variable was evolved after each increment of cycles $(\Delta N)$ based on the damage evolution law (Eq. 7). Then the cohesive zone model response was degraded based on the fatigue damage variable. It is worth noting that this fatigue damage variable was only used to degrade the CZM parameters and not in the formulation of the CZM. After completing the first CA stage, the load was changed to the maximum fatigue 
load of the second CA stage in the VA spectrum and the same degrading process was implemented. The material degradation process mentioned above was repeated until the damaged joint could no longer sustain the applied maximum fatigue load, at which point the joint failed. As the material degradation in the fatigue model is implemented in increments of cycles ( $\Delta N)$ until the joint failure (collapse), the fatigue life can simply be determined by summing the increments of cycles. Fig. 9 shows a VA fatigue loading spectrum which consists of two CA fatigue stages with different characteristics (defined by different $P_{\max }$ and load ratio).

\section{Fig. 9. Fatigue degradation of cohesive elements}

This approach can easily be extended to a VA fatigue loading with more than two CA fatigue stages. As shown in Fig. 9, each CA fatigue stage, depending on the loading characteristics, has different incremental damage growth rates which can be determined using Eq. 7.

The fatigue damage model parameters $\left(\alpha, \beta, \bar{\varepsilon}_{t h}, n\right.$ and $\left.m\right)$ need to be calibrated against the experimental tests to predict the fatigue failure response of the bonded joints. A parametric study was undertaken to study the effect of fatigue damage model parameters on the load-life curves. The parameter $m$ can be determined by correlating the empirical constant-life equations (Eq. 5) with the experimental results. Increasing the value of $\beta$ and the threshold averaged bondline thickness strain $\left(\bar{\varepsilon}_{t h}\right)$ decelerate the damage evolution and increase the lifetime, while increasing the constant $\alpha$ accelerates the damage evolution and consequently decreases the predicted fatigue lifetime. Furthermore, changing the constant $\alpha$ leads to a shift of the load-life (P-N) curve in the horizontal direction (N-direction). However, increasing $\beta$ decreases the slope of the P-N curve by decelerating the fatigue damage more at lower averaged bondline thickness strain (load) levels. This is due to the fact that the averaged bondline thickness strains in the adhesive are small $(<1)$ and thus at lower fatigue load levels they reduce more rapidly with the power $\beta$ (when $\beta>1$ ). The parameter $n$ is introduced to accommodate the ductility of the adhesive and the sensitivity of the adhesive system to the variation of the load ratio. An informed iterative approach was undertaken to determine appropriate fatigue model parameter values, which are summarised in Table 3.

Table 3. The fatigue damage model parameters 


\begin{tabular}{ccccc}
\hline $\boldsymbol{\alpha}$ & $\boldsymbol{\beta}$ & $\overline{\boldsymbol{\varepsilon}}_{\text {th }}$ & $\mathbf{m}$ & $\mathbf{n}$ \\
\hline 4 & 2 & 0.0265 & 2 (Gerber) & 2
\end{tabular}

The fatigue damage model parameters $\left(\alpha, \beta, \bar{\varepsilon}_{t h}\right.$, and $\left.n\right)$ were obtained by correlating the experimental and numerical load-life results of the SLJs under CA fatigue loading. It should be noted that the parameter $m$ was considered 2 as it was shown in [10] that the FM 73M adhesive follows the Gerber response for the effect of load ratio. Fig. 10 shows the comparison between the experimental and numerical results for CA fatigue.

Fig. 10. Experimental and numerical CA fatigue load-life data

Then, these parameters were used to predict the structural behaviour of adhesively bonded joints under the VA fatigue loading. Fig. 11 compares the experimental load-life results with the predicted results obtained using the proposed model for the various VA fatigue loading spectra discussed earlier.

Fig. 11. Comparison of experimental and predicted fatigue cycles to failure for various VA fatigue loading spectra

The percentage errors between the experimental fatigue lives and the numerical results obtained using various predictive models for the different types of VA fatigue loading spectra are summarised in Table 4.

Table 4. Comparison between experimental and numerical fatigue lives predicted using different methods

\begin{tabular}{|c|c|c|c|c|}
\hline \multirow{2}{*}{$\begin{array}{c}\text { VA fatigue } \\
\text { Loading } \\
\text { spectra }\end{array}$} & \multicolumn{4}{|c|}{$\%$ Error } \\
\hline & $\begin{array}{c}\text { Palmgren- } \\
\text { Miner (PM) }\end{array}$ & $\begin{array}{c}\text { Fracture } \\
\text { mechanics [9] }\end{array}$ & $\begin{array}{c}\text { Damage } \\
\text { mechanics [9] }\end{array}$ & $\begin{array}{c}\text { Proposed model } \\
\text { CZM }\end{array}$ \\
\hline $\mathrm{A}$ & 25 & -70 & 72 & -4 \\
\hline B & $63^{*}$ & -76 & 17 & -5 \\
\hline $\mathrm{C}$ & $2^{*}$ & -79 & 31 & -24 \\
\hline $\mathrm{D}$ & $103^{*}$ & -70 & 94 & -7 \\
\hline
\end{tabular}

* calculated using the predicted results

It should be noted that for calculating the fatigue life using the PM rule, individual experimental results of each CA fatigue stage in the VA fatigue loading spectra were required. 
However, only the experimental CA fatigue results for load ratio of 0.1 were available in [9], thus the CA fatigue results for other load ratios were obtained numerically using the proposed fatigue model where necessary.

As can be seen from Table 4, the fracture mechanics based model significantly underpredicted the fatigue lifetime for all loading spectra. This was because the fracture mechanics based models ignore the initiation phase of the fatigue life. Furthermore, the PM rule and the damage mechanics based model considerably over-predicted for all loading spectra. The overprediction of the PM rule can be attributed to the damage accelerative load interaction effect of the VA fatigue loading on the adhesively bonded joint that is not accommodated in the PM approach. In principal, it would be possible to amend the approaches we compare against. For example, the facture mechanics based approach could be used together with the stress singularity based approach to take the initiation phase of the fatigue life into account and enhance the results. As is evident from Table 4, the proposed fatigue model was found to successfully predict the fatigue lives for the various types of VA fatigue loading spectra.

The crack was simulated by removing the fully damaged cohesive elements. It should be noted that as the analysis was symmetric, two cracks grew symmetrically, one from each overlap end. Fig. 12 shows the variation of the crack length with the number of cycles predicted by the proposed fatigue model for the SLJ subjected to the four types of the VA loading spectra and the corresponding CA loading stages. It can be seen that in all cases, the crack growth rate for the VA loading was between the crack growth rates of the corresponding CA loading stages. Moreover, considering the predicted CA crack growths, it can be seen from Table 1 that although the load ratio increased (type B) or decreased (type D) the crack growth rate of the second stage was always quicker. The second stage in types B and $\mathrm{D}$ had the same increase in maximum fatigue load implying that the crack growth rate is mostly governed by the maximum fatigue load level in CA loading. Moreover, as can be seen from Fig. 12, in all the four VA spectra the crack growth rate was closer to the crack growth rate of the more severe CA loading stage (CA stage 2), even though the number of cycles of the more severe CA loading stage in the VA spectra $\left(n_{2}\right)$ was half or less than the number of cycles of the other CA loading stage $\left(n_{1}\right)$, see Table 1 . This was the case even for the type $\mathrm{D}$ spectrum (see Fig. 12(d)) in which $n_{1}$ and $n_{2}$ were 1 and 10, respectively. 
It can be seen from the CA crack growths curves (Fig. 12) that the CA loading stage with the lower maximum fatigue load level (CA stage 1) had a longer crack length before final failure. That was because a smaller ligament of undamaged adhesive was required to sustain this lower maximum fatigue load level. Furthermore, the VA crack length before final failure for type D loading was noticeably shorter than the crack length of the more severe CA stage (CA stage 2) before final failure, although the maximum fatigue loads of the VA spectrum were either the same as the maximum fatigue load of the more severe CA stage (CA stage 2) or less than this value (CA stage 1). This was somewhat surprising but further analysis of the numerical data showed that more loading cycles were applied before the final failure and most of these were at the lower level of loading (i.e. CA stage 1) which produced damage that was more uniformly spread although slower in rate. As this damage was more widespread, a longer ligament of adhesive was required to prevent static failure at the higher maximum fatigue load (i.e. in stage 2). The damage was more widespread at the lower fatigue load because the averaged bondline thickness strain is raised to a power in the fatigue damage model (Eq. 7) and this concentrates the damage more at the overlap ends in the more highly strained case of the higher Stage 2 maximum fatigue load.

Fig. 12. Crack growth of the VA loading spectra and the corresponding CA stages for spectra a) type A, b) type $B$, c) type $C$ and d) type $D$

It is well-known that the crack in adhesively bonded joints can propagate either within the adhesive or on the interface. Interfacial failure due to a weaker interface would be reflected in lower fracture energy and tripping traction values (i.e. considered as a material parameter of the bonding system). There is evidence that, as long as the failure is cohesive, whether it is at the centre of the bond or closer to the interface does not significantly affect the measured joint strength and hence a single layer of cohesive zone elements is acceptable.

The predicted process (damage) zone length of the VA loading spectra and the corresponding CA stages detected ahead of a crack propagated $1 \mathrm{~mm}$ inside the overlap is shown in Fig. 13. As can be seen in Fig. 13, the process zone length predicted for the VA loading spectra was equal to the process zone length predicted for the more severe CA loading stage (CA stage 2), except for type B which was slightly smaller (which the authors believe is due to the higher load ratio of the stage 2 cycles). Considering that $n_{2} / n_{1}$ ratio for the spectra $\mathrm{A}, \mathrm{B}$ and $\mathrm{C}$ was 0.5 and for the spectrum D was 0.1 , this implies that the presence of even a few cycles with 
faster crack growth in the VA fatigue loading spectrum increases the process (damage) zone length. This phenomenon is consistent with experimental observations [3].

Fig. 13. Predicted process zone length of the VA loading spectra and the corresponding CA stages a head of the crack propagated $1 \mathrm{~mm}$ inside the overlap

A predictive fatigue model should be geometry independent. This means that having determined the model parameters for a bonded joint, the model parameters can be applied for another bonded joint with the same adhesive system (with the same adhesive material and surface pre-treatment) but different geometry. This point was confirmed for a simpler version of the proposed fatigue model [33] for CA fatigue by applying the model to two different bonded joints. However, a further study would be required to fully confirm the predictive capability of the generalised model outlined in this paper.

\section{Conclusions}

The fatigue behaviour of the adhesively bonded joints under variable amplitude cyclic loading was predicted using a numerical fatigue damage model. This model was based on a cohesive zone model integrated with a fatigue damage model. The following conclusions were drawn:

a) The fatigue load was characterised with the maximum fatigue load level. To incorporate the influence of load ratio, a correction factor, (a function of load ratio) was determined. The effect of utilising this correction factor for modifying either the maximum fatigue load or the fatigue damage equation was investigated. It was found that although both of the modifications could successfully predict the fatigue life, only the results obtained by modifying the fatigue damage evolution were consistent with the backface strain data and thus the measured fatigue damage rate. Thus the correction factor was used to modify the fatigue damage equation.

b) The results predicted using the proposed model were compared with the results obtained from other predictive approaches. It was found that the proposed model could successfully predict the fatigue life of the adhesively bonded joints while the other approaches considered either significantly under-predictive or over-predictive the lives.. 
c) Comparison between the crack growth rates predicted for the VA loading spectra with the ones predicted for the corresponding CA loading stages revealed that the presence of even a small proportion of overloads in the VA fatigue loading spectrum increases the process (damage) zone and consequently accelerates the damage growth considerably.

\section{References}

[1] I. A. Ashcroft, 2005, Fatigue. In R. D. Adams (Ed.), Adhesive bonding: Science, technology and applications: 209-39. Woodhead Publishing Limited and CRC Press LLC.

[2] Chen DH, Nisitani H. Analysis of the Delaying Effects of Overloads on Fatigue CrackPropagation. Engineering Fracture Mechanics 1991;39:287-98.

[3] Erpolat S, Ashcroft IA, Crocombe AD, Abdel-Wahab MM. A study of adhesively bonded joints subjected to constant and variable amplitude fatigue. International Journal of Fatigue 2004;26:1189-96.

[4] Schaff JR, Davidson BD. Life prediction methodology for composite structures .2. Spectrum fatigue. Journal of Composite Materials 1997;31:158-81.

[5] Chang JB, Szamossi M, Liu KW. Random spectrum fatigue crack life predictions with or without considering load interactions. ASTM Special Technical Publication $1981 ; 115-32$.

[6] Miner MA. Cumulative Damage in Fatigue. Journal of Applied Mechanics-Transactions of the ASME 1945;12:A159-A164.

[7] Shenoy V, Ashcroft IA, Critchlow GW, Crocombe AD, Wahab MMA. An evaluation of strength wearout models for the lifetime prediction of adhesive joints subjected to variable amplitude fatigue. International Journal of Adhesion and Adhesives 2009;29:639-49.

[8] Ashcroft IA. A simple model to predict crack growth in bonded joints and laminates under variable-amplitude fatigue. Journal of Strain Analysis for Engineering Design 2004;39:707-16.

[9] Shenoy V, Ashcroft IA, Critchlow GW, Crocombe AD. Fracture mechanics and damage mechanics based fatigue lifetime prediction of adhesively bonded joints subjected to variable amplitude fatigue. Engineering Fracture Mechanics 2010:77:1073-1090.

[10] Khoramishad H, Crocombe AD, Katnam KB, Ashcroft IA. A generalised damage model for constant amplitude fatigue loading of adhesively bonded joints. International Journal of Adhesion and Adhesives 2010:30:513-521. 
[11] Palmgren A. The lifespan of swivel heads. Zeitschrift des Vereines Deutscher Ingenieure 1924;68:339-41.

[12] Shenoy V, Ashcroft IA, Critchlow GW, Crocombe AD, Wahab MMA. Strength wearout of adhesively bonded joints under constant amplitude fatigue. International Journal of Fatigue 2009;31:820-30.

[13] Schaff JR, Davidson BD. Life prediction methodology for composite structures .1. Constant amplitude and two-stress level fatigue. Journal of Composite Materials 1997;31:128-57.

[14] Erpolat S, Ashcroft IA, Crocombe AD, Abdel-Wahab MM. Fatigue crack growth acceleration due to intermittent overstressing in adhesively bonded CFRP joints. Composites Part A-Applied Science and Manufacturing 2004;35:1175-83.

[15] O'Brien T.K., 1982, Characterisation of delamination onset and growth in a composite laminate, Damage in Composite Materials, ASTM STP 775, 20: 140-167.

[16] Wahab MMA, Ashcroft IA, Crocombe AD, Shaw SJ. Prediction of fatigue thresholds in adhesively bonded joints using damage mechanics and fracture mechanics. Journal of Adhesion Science and Technology 2001;15:763-81.

[17] Imanaka M, Hamano T, Morimoto A, Ashino R, Kimoto M. Fatigue damage evaluation of adhesively bonded butt joints with a rubber-modified epoxy adhesive. Journal of Adhesion Science and Technology 2003;17:981-94.

[18] Roe KL, Siegmund T. An irreversible cohesive zone model for interface fatigue crack growth simulation. Engineering Fracture Mechanics 2003:70:209-232.

[19] Turon A, Costa J, Camanho PP, Davila CG. Simulation of delamination in composites under high-cycle fatigue. Composites part A-applied science and manufacturing 2007:38:2270-2282.

[20] Turon A, Costa J, Camanho PP, Maimi P. Analytical and numerical investigation of the length of the cohesive zone in delaminated composite materials. Mechanical response of composites 2008:10:77-97.

[21] Yang QD, Shim DJ, Spearing SM. A cohesive zone model for low cycle fatigue life prediction of solder joints. Microelectronic engineering 2004:75:85-95.

[22] Siegmund T. A numerical study of transient fatigue crack growth by use of an irreversible cohesive zone model. International Journal of Fatigue 2004:26:929-939.

[23] Jiang HD, Gao XS, Srivatsan TS. Predicting the influence of overload and loading mode on fatigue crack growth: A numerical approach using irreversible cohesive elements. Finite Elements in Analysis and Design 2009:45:675-685.

[24] Critchlow GW, Ashcroft IA, Cartwright T, Bahrani D. Anodising aluminium alloy. UK patent no. GB 2421959A 2006. 
[25] Abe H, Satoh T. Non-destructive detection method of fatigue crack in spot-welded joints. Yosetsu Gakkai Ronbunshu/Quarterly Journal of the Japan Welding Society 1986;4:666-73.

[26] Zhang ZH, Shang JK, Lawrence FV. A Backface Strain Technique for Detecting Fatigue-Crack Initiation in Adhesive Joints. Journal of Adhesion 1995;49:23-36.

[27] Crocombe AD, Ong CY, Chan CM, Wahab MMA, Ashcroft IA. Investigating fatigue damage evolution in adhesively bonded structures using backface strain measurement. Journal of Adhesion 2002;78:745-76.

[28] Graner Solana A, Crocombe AD, Wahab MMA, Ashcroft IA. Fatigue initiation in adhesively-bonded single-lap joints. Journal of Adhesion Science and Technology 2007;21:1343-57.

[29] Atlas of stress-strain curves, ASM International, 2002.

[30] Barenblatt GI. Equilibrium Cracks Formed on A Brittle Fracture. Doklady Akademii Nauk Sssr 1959;127:47-50.

[31] Barenblatt GI. The mathematical theory of equilibrium cracks in brittle fracture. Advances in Applied Mechanics 1962;7:55-129.

[32] Hillerborg A, Modeer M, Petersson PE. Analysis of crack formation and crack growth in concrete by means of fracture mechanics and finite elements. Cement and Concrete Research 1976;6:773-81.

[33] Khoramishad H, Crocombe AD, Katnam KB, Ashcroft IA. Predicting fatigue damage in adhesively bonded joints using a cohesive zone model. International Journal of Fatigue 2010;32:1146-58.

[34] Benzeggagh ML, Kenane M. Measurement of mixed-mode delamination fracture toughness of unidirectional glass/epoxy composites with mixed-mode bending apparatus. Composites Science and Technology 1996:56:439-449. 


\begin{tabular}{|ll|}
\hline Nomenclature & \\
$E_{\mathrm{I}}, E_{\mathrm{II}}$ & initial stiffnesses for mode I and mode II \\
$G_{I}, G_{I I}$ & energy release rates in mode I and mode II \\
$G_{\mathrm{IC}}, G_{\mathrm{IIC}}$ & fracture energies for mode I and mode II \\
$n_{\mathrm{i}(i=1,2, \ldots)}$ & number of cycles in the CA stage \\
$n_{\mathrm{S}}$ & number of CA stages in the VA loading block \\
$P_{\mathrm{a}}$ & fatigue load amplitude \\
\hline$P_{a}$ & equivalent load amplitude at the load ratio of -1 \\
$P_{\mathrm{m}}$ & mean fatigue load \\
$P_{\mathrm{max}}, P_{\mathrm{min}}$ & maximum and minimum fatigue load \\
$P_{\mathrm{S}}$ & static strength \\
$R$ & load ratio \\
$T_{\mathrm{I}}, T_{\mathrm{II}}$ & tripping tractions for mode I and mode II \\
$t_{\mathrm{I}}, t_{I I}$ & tractions in mode I and mode II \\
$\alpha, \beta, m$ and $n$ & fatigue damage model parameters \\
$\Delta D$ & increment of damage \\
$\Delta N$ & cycle increment \\
$\varepsilon_{n}, \varepsilon_{s}$ & normal and shear strain components \\
$\varepsilon_{\text {max }}$ & maximum principal strain \\
$\varepsilon_{\text {th }}$ & threshold strain \\
$\mathrm{Abbreviations}$ & \\
$\mathrm{CA}$ & \\
$\mathrm{CZM}$ & constant amplitude \\
$\mathrm{PM}$ & cohesive zone model \\
$\mathrm{SLJ}$ & valmgren-miner \\
$\mathrm{VA}$ & \\
& \\
&
\end{tabular}




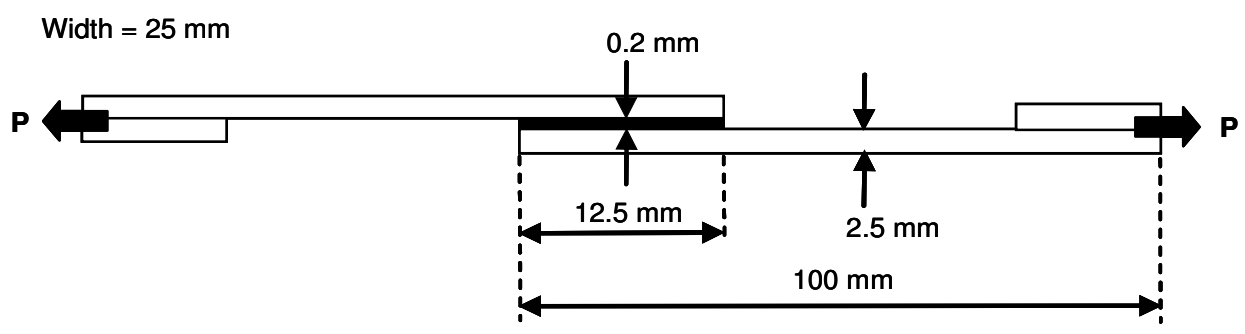

Fig. 1. Single lap joint 
Error! Reference source not found.

Fig. 2. Various VA fatigue loading spectra 

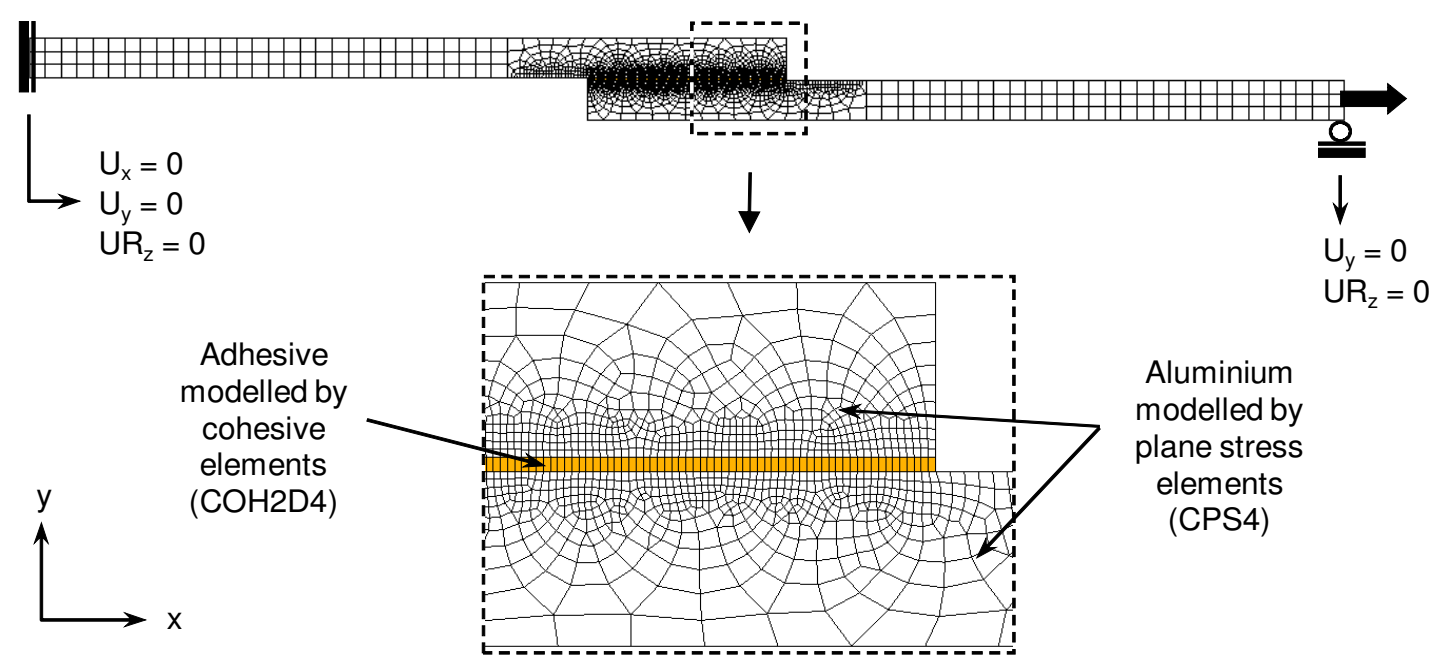

Aluminium

modelled by

plane stress

elements

(CPS4)

Fig. 3. Finite element mesh and boundary conditions 


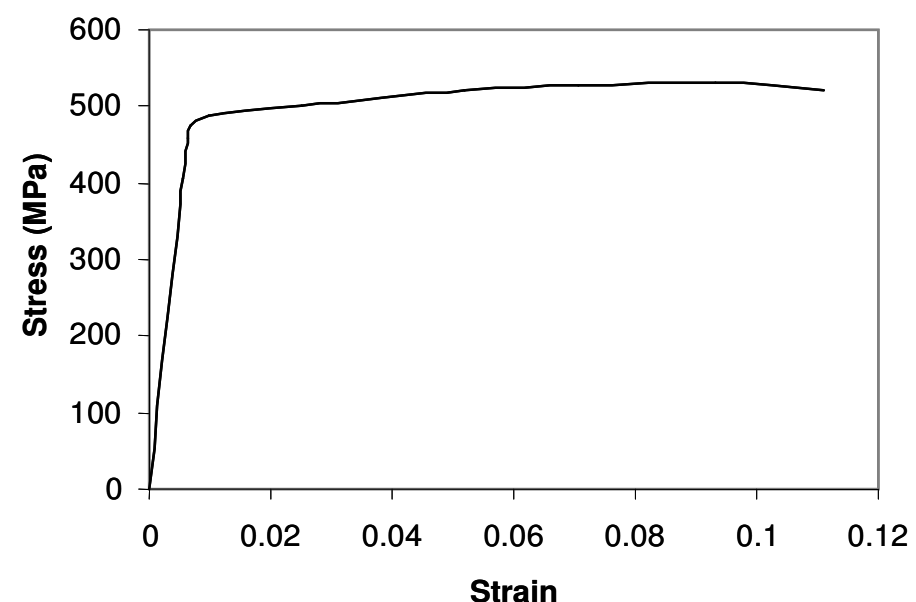

Fig. 4. Stress-strain curve for 7075-T6 aluminium alloy [29] 


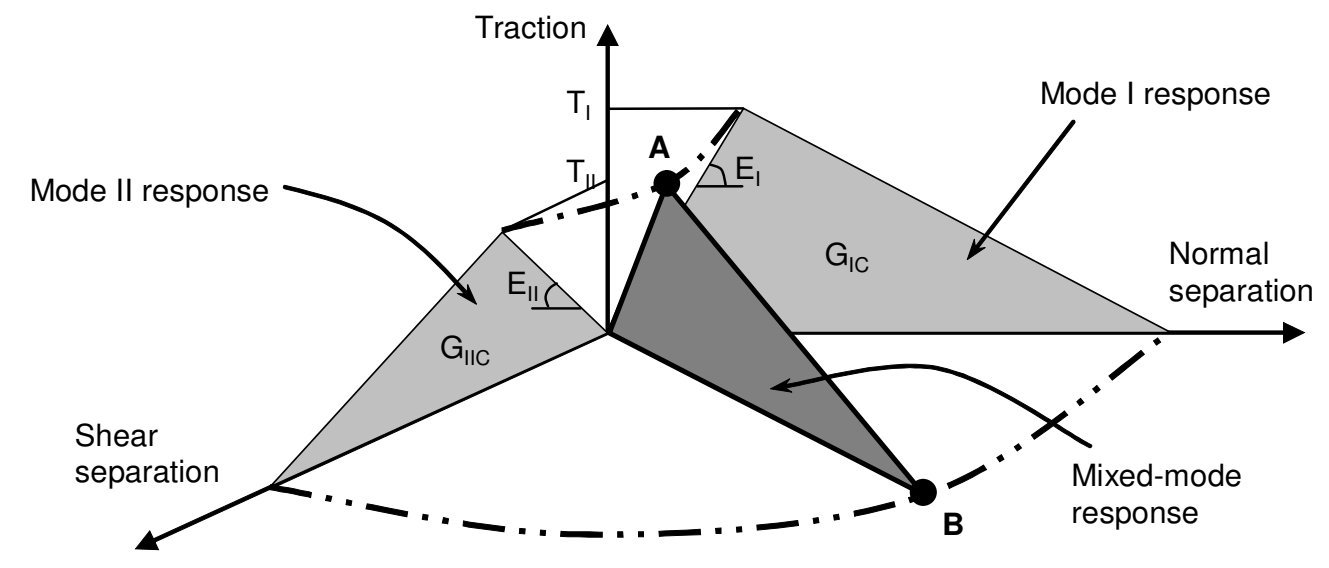

- - Damage initiation criterion

- .. Damage propagation criterion

Fig. 5. Mixed-mode bi-linear traction-separation law 


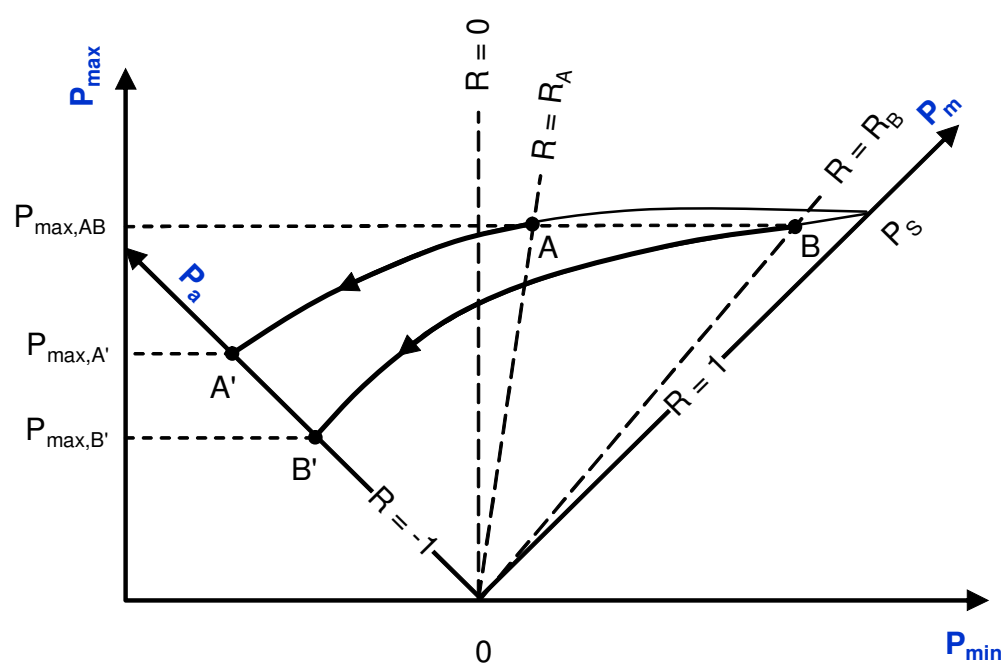

Fig. 6. A schematic of fatigue master diagram 
Error! Reference source not found.

Fig. 7. Fatigue model modifications 


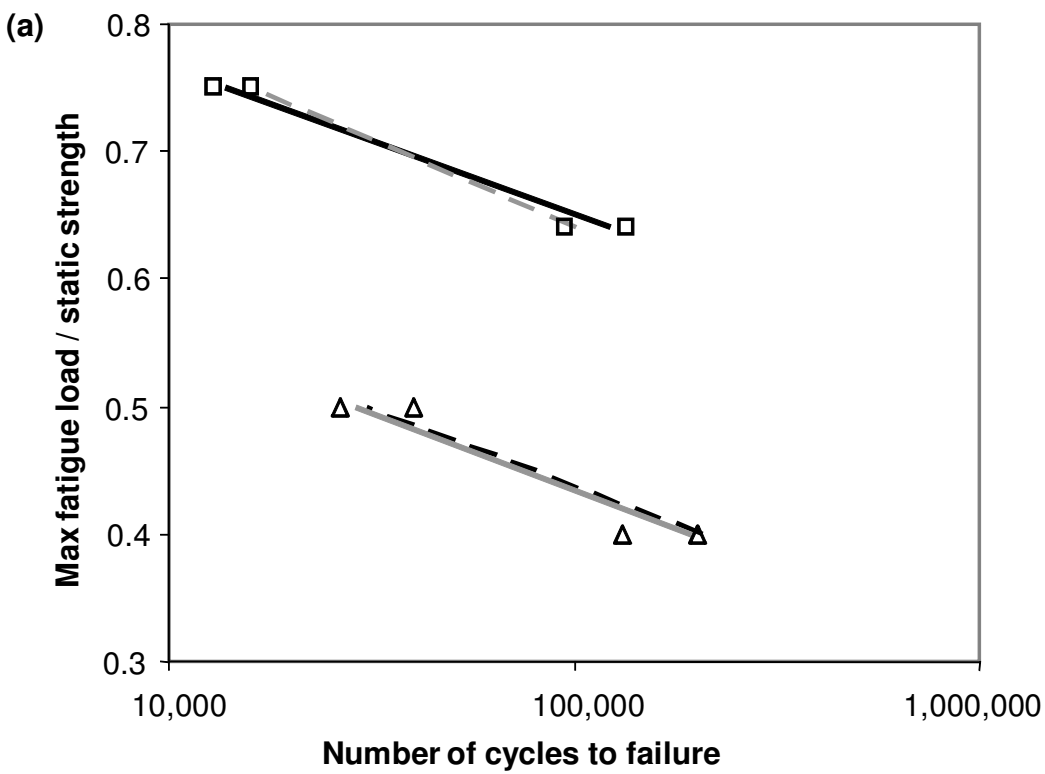

$$
\begin{aligned}
& \text { - Damage evolution modification } R=0.5 \text { (Num) } \\
& \text { - D Damage evolution modification } R=0.1 \text { (Num) } \\
& \square \quad R=0.5 \text { (Exp) } \\
& --P_{\max } \text { modification } R=0.5 \text { (Num) } \\
& \hline \quad P_{\max } \text { modification } R=0.1 \text { (Num) } \\
& \Delta \quad R=0.1 \text { (Exp) }
\end{aligned}
$$

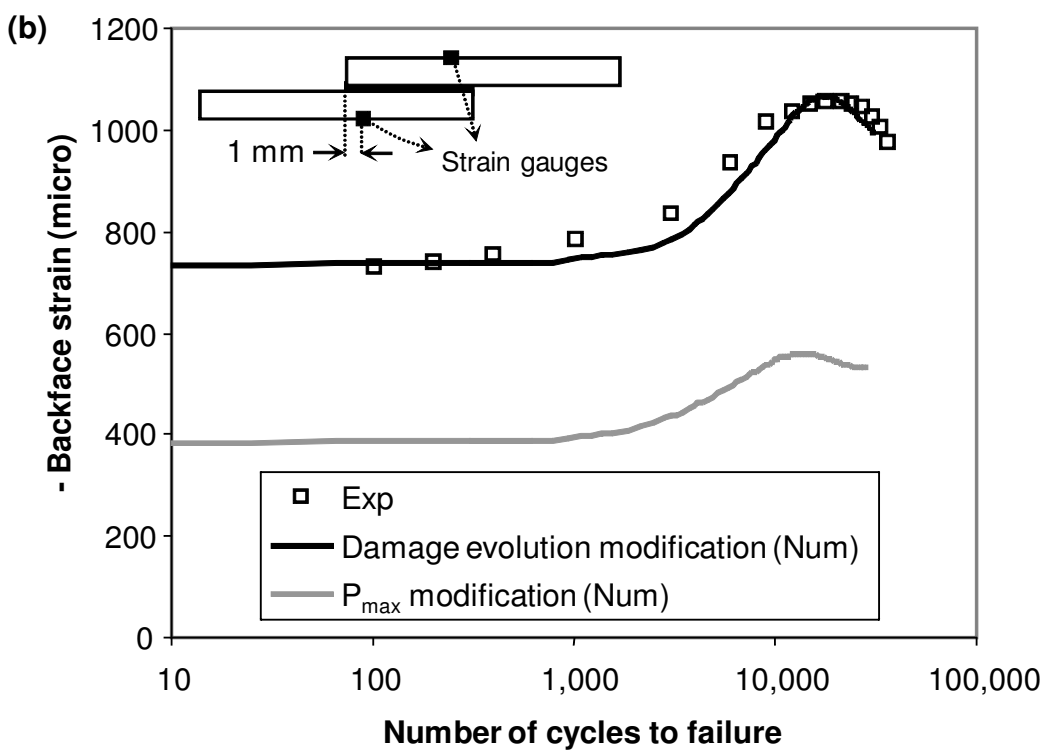

Fig. 8. Comparison between the $P_{\max }$ and fatigue damage evolution law modifications, a) load-life data, $b$ ) backface strain data for $R=0.1$ and $P_{\text {max }} / P_{S}=0.5$ 


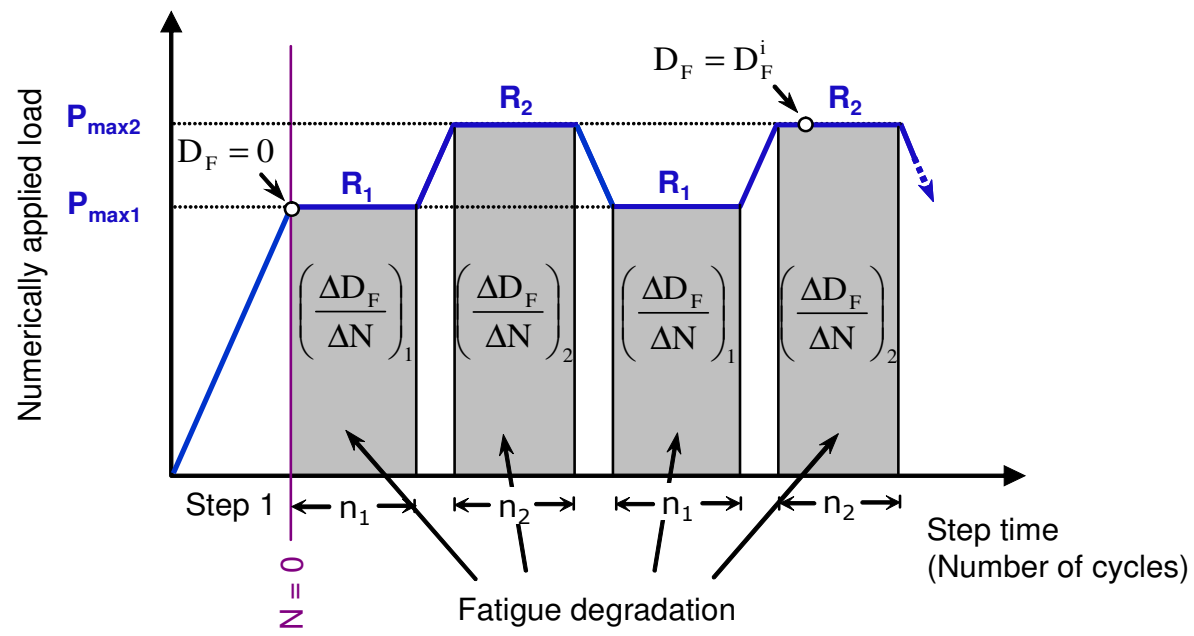

(Step 2)

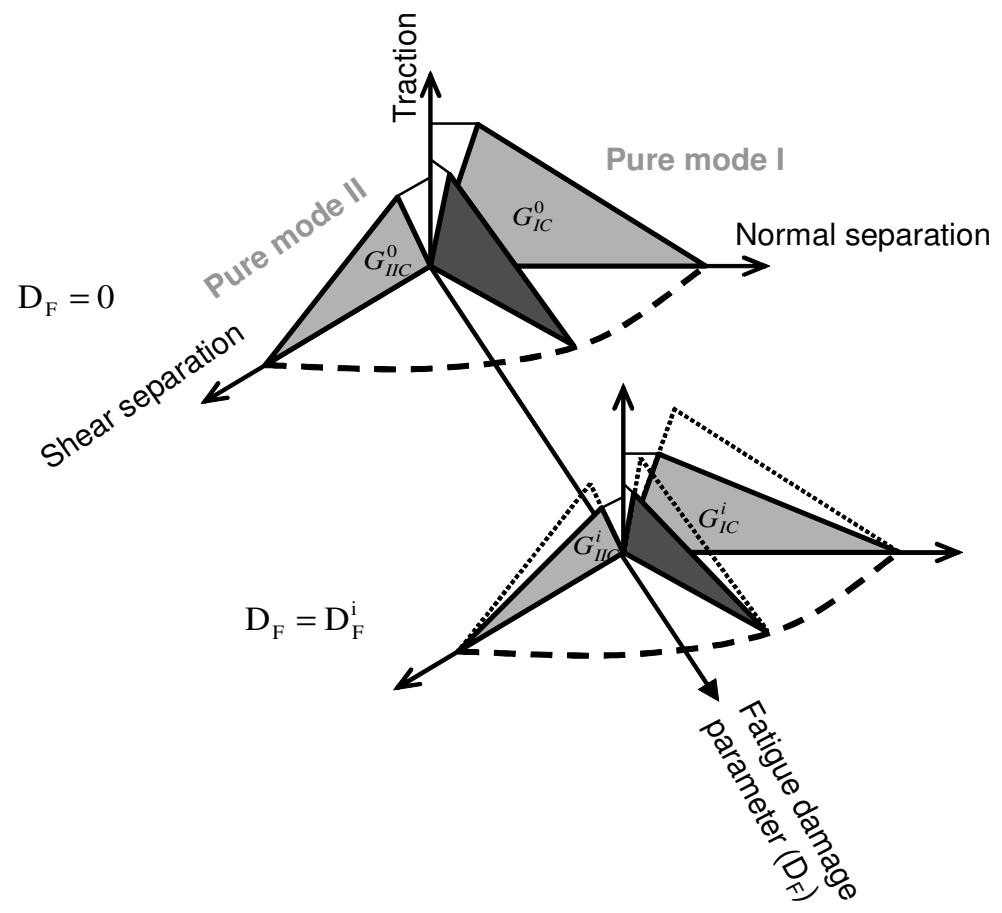

Fig. 9. Fatigue degradation of cohesive elements 


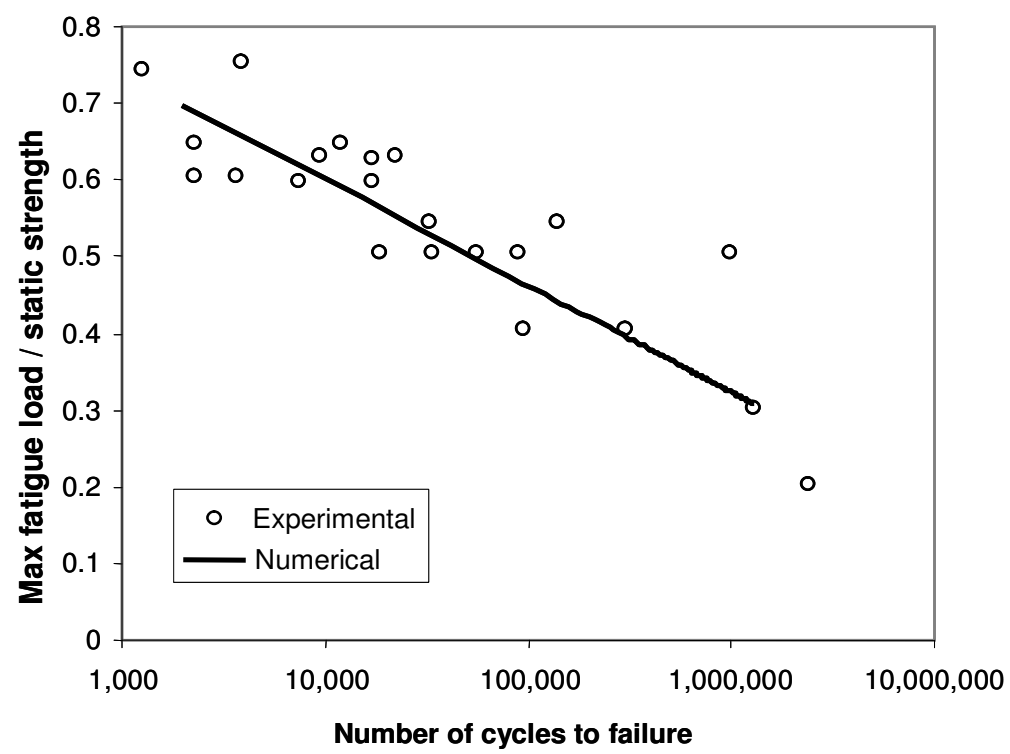

Fig. 10. Experimental and numerical CA fatigue load-life data 


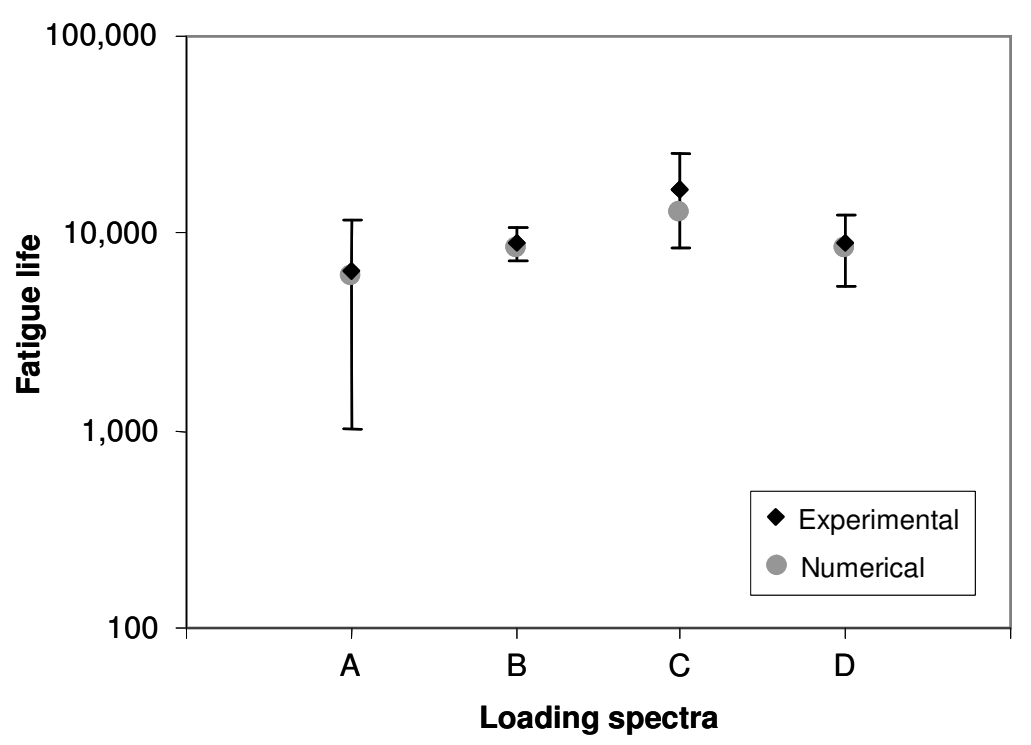

Fig. 11. Comparison of experimental and predicted fatigue cycles to failure for various VA fatigue loading spectra 

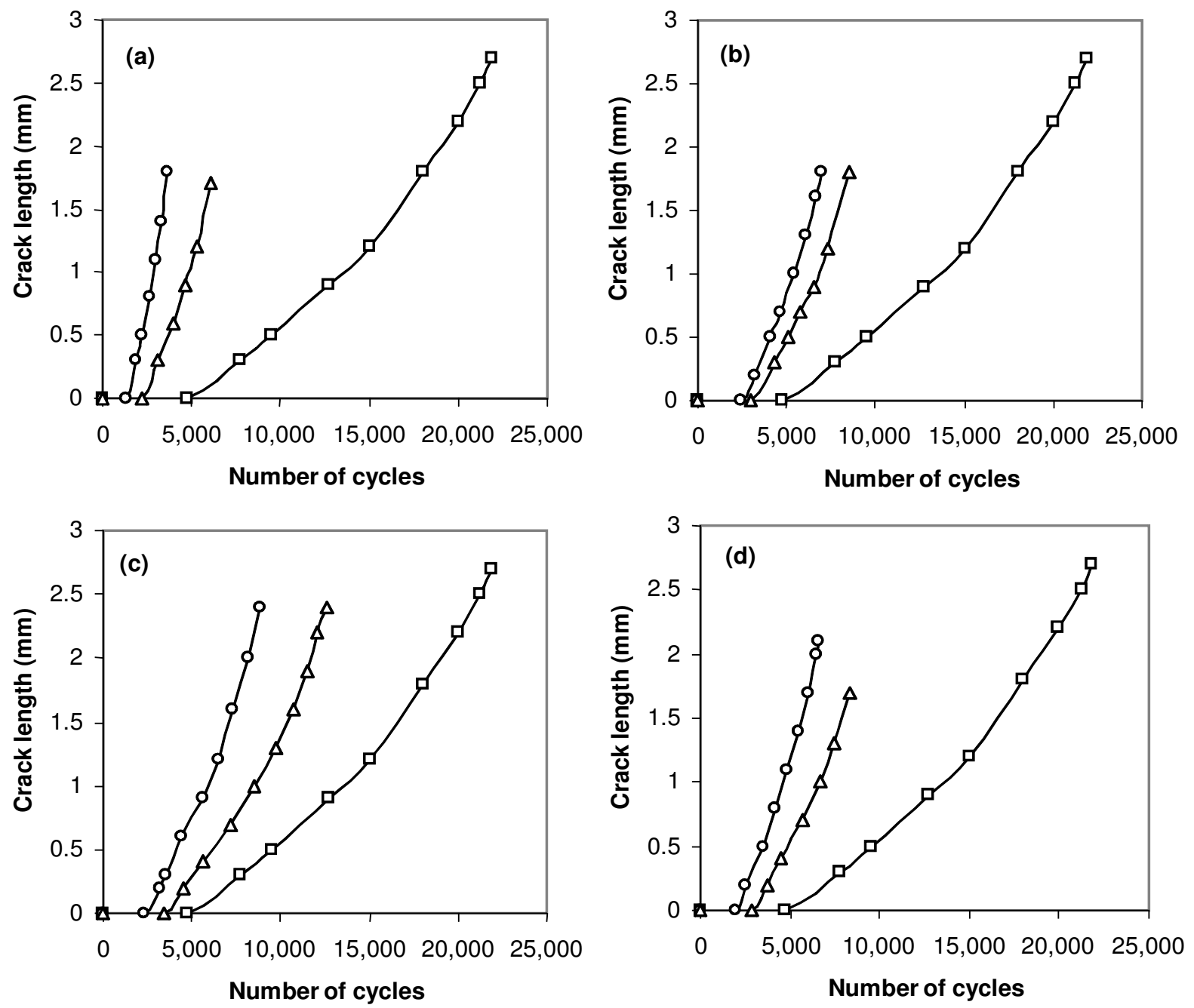

$\neg \square$ CA stage $1 \multimap$ CA stage $2 \multimap-V A$ loading

Fig. 12. Predicted crack growth of the VA loading spectra and the corresponding CA stages for spectra a) type A, b) type B, c) type C and d) type D 


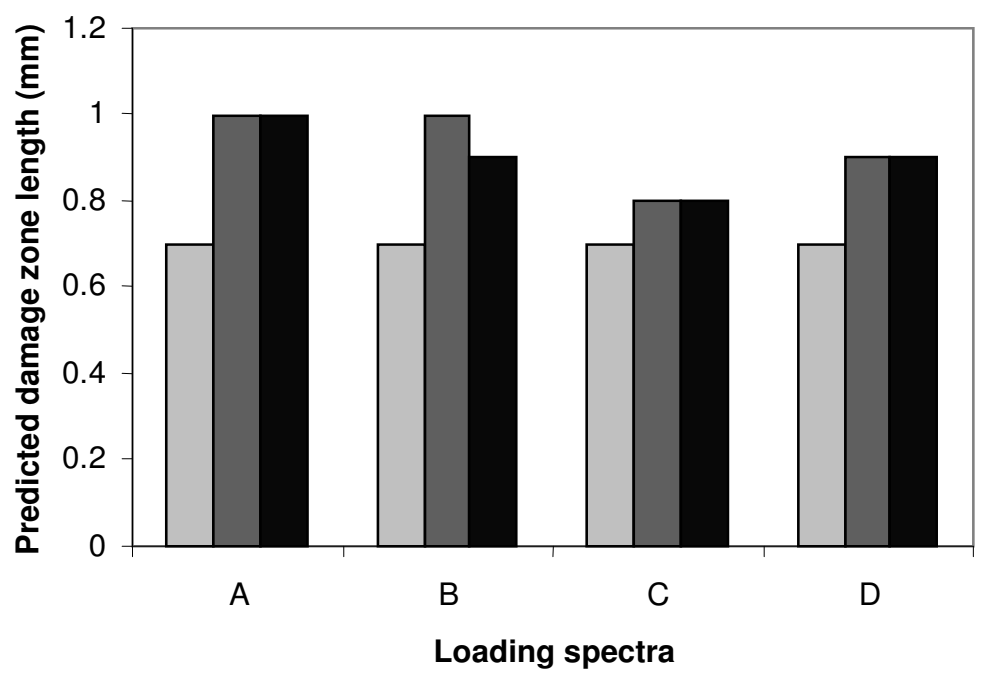

$\square$ CA stage $1 \square$ CA stage $2 \square \mathrm{VA}$ loading

Fig. 13. Predicted process zone length of the VA loading spectra and the corresponding CA stages a head of the crack propagated $1 \mathrm{~mm}$ inside the overlap 
Table 1. VA fatigue loading spectra descriptions

\begin{tabular}{|c|c|c|c|c|c|c|c|c|c|}
\hline \multirow{2}{*}{$\begin{array}{c}\text { VA fatigue } \\
\text { loading } \\
\text { spectra }\end{array}$} & \multicolumn{4}{|c|}{ Loading conditions } & \multicolumn{2}{|c|}{ Cycles } & \multicolumn{3}{|c|}{$\%$ changes in } \\
\hline & $\begin{array}{l}P_{\max 1} \\
(k N)\end{array}$ & $\begin{array}{l}P_{\max 2} \\
(k N)\end{array}$ & $\mathbf{R}_{1}$ & $\mathbf{R}_{2}$ & $\mathbf{n}_{1}$ & $\mathbf{n}_{2}$ & $\mathbf{R}$ & $\mathbf{P}_{\mathbf{a}}$ & $\mathbf{P}_{\mathrm{m}}$ \\
\hline $\mathbf{A}$ & 6.5 & 8 & 0.1 & 0.1 & 10 & 5 & 0 & 23 & 23 \\
\hline $\mathbf{B}$ & 6.5 & 8 & 0.1 & 0.27 & 10 & 5 & 169 & 0 & 42 \\
\hline $\mathbf{C}$ & 6.5 & 7 & 0.1 & 0.02 & 10 & 5 & -80 & 17 & 0 \\
\hline D & 6.5 & 8 & 0.1 & 0.08 & 10 & 1 & -19 & 26 & 21 \\
\hline
\end{tabular}


Table 2. Calibrated traction-separation response

\begin{tabular}{cccc}
\hline $\begin{array}{c}\text { Tripping traction } \\
\text { normal (shear) } \\
\mathbf{M P a}\end{array}$ & $\begin{array}{c}\text { Fracture energy } \\
\text { mode I (mode II) } \\
\mathbf{k J} / \mathbf{m}^{\mathbf{2}}\end{array}$ & Initiation criterion & Propagation criterion \\
\hline $72(42)$ & $2(4)$ & $\begin{array}{c}\text { Maximum nominal } \\
\text { stress criterion }\end{array}$ & $\begin{array}{c}\text { Benzeggagh-Kenane (BK) } \\
(\text { with } \eta=2)\end{array}$ \\
\hline
\end{tabular}


Table 3. The fatigue damage model parameters

\begin{tabular}{ccccc}
\hline $\boldsymbol{\alpha}$ & $\boldsymbol{\beta}$ & $\boldsymbol{\varepsilon}_{\text {th }}$ & $\mathbf{m}$ & $\mathbf{n}$ \\
\hline 4 & 2 & 0.0265 & 2 (Gerber) & 2
\end{tabular}


Table 4. Comparison between experimental and numerical fatigue lives predicted using different methods

\begin{tabular}{|c|c|c|c|c|}
\hline \multirow{2}{*}{$\begin{array}{c}\text { VA fatigue } \\
\text { Loading } \\
\text { spectra }\end{array}$} & \multicolumn{4}{|c|}{$\%$ Error } \\
\hline & $\begin{array}{r}\text { Palmgren- } \\
\text { Miner (PM) }\end{array}$ & $\begin{array}{c}\text { Fracture } \\
\text { mechanics [9] }\end{array}$ & $\begin{array}{c}\text { Damage } \\
\text { mechanics [9] }\end{array}$ & $\begin{array}{c}\text { Proposed model } \\
\text { CZM }\end{array}$ \\
\hline $\mathrm{A}$ & 25 & -70 & 72 & -4 \\
\hline B & $63^{*}$ & -76 & 17 & -5 \\
\hline $\mathrm{C}$ & $2^{*}$ & -79 & 31 & -24 \\
\hline $\mathrm{D}$ & $103^{*}$ & -70 & 94 & -7 \\
\hline
\end{tabular}

*alculated using the predicted results 